\title{
Development and Application of MCNP5 and KENO-VI Monte Carlo Models for the Atucha-2 PHWR Analysis
}

\author{
M. Pecchia, ${ }^{1}$ C. Parisi, ${ }^{1}$ F. D'Auria, ${ }^{1}$ and O. Mazzantini ${ }^{2}$ \\ ${ }^{1}$ San Piero a Grado Nuclear Research Group (GRNSPG), University of Pisa, via Diotisalvi 2, 56122 Pisa, Italy \\ ${ }^{2}$ Nucleoelectrica Argentina-Societad Anonima (NA-SA), C1429BKQ Buenos Aires, Argentina \\ Correspondence should be addressed to M. Pecchia, marco.pecchia@ing.unipi.it
}

Received 22 September 2010; Accepted 2 December 2010

Academic Editor: Juan Ferreri

Copyright (C 2011 M. Pecchia et al. This is an open access article distributed under the Creative Commons Attribution License, which permits unrestricted use, distribution, and reproduction in any medium, provided the original work is properly cited.

\begin{abstract}
The geometrical complexity and the peculiarities of Atucha-2 PHWR require the adoption of advanced Monte Carlo codes for performing realistic neutronic simulations. Core models of Atucha-2 PHWR were developed using both MCNP5 and KENOVI codes. The developed models were applied for calculating reactor criticality states at beginning of life, reactor cell constants, and control rods volumes. The last two applications were relevant for performing successive three dimensional neutron kinetic analyses since it was necessary to correctly evaluate the effect of each oblique control rod in each cell discretizing the reactor. These corrective factors were then applied to the cell cross sections calculated by the two-dimensional deterministic lattice physics code HELIOS. These results were implemented in the RELAP-3D model to perform safety analyses for the licensing process.
\end{abstract}

\section{Introduction}

In the framework of the agreement NA-SA-University of Pisa no. 2", several technical and research activities are being performed at the GRNSPG of the University of Pisa, in order to analyze the main characteristics of the plant and its behavior during normal and accidental conditions. In this paper, we present the activities performed using the Monte Carlo MCNP5 and KENO-VI codes, or the Atucha-2 fullcore model development, some criticality calculations, its use for the RELAP5-3D three-dimensional neutron kinetics model development and validation, and then a result of a transient calculation using the validated RELAP5-3D model.

Atucha-2 is a 693 MWe Siemens designed PHWR under construction in the Republic of Argentina (see Figure 1). Its core is composed by 451 fuel bundles placed in vertical Fuel Channels which are arranged in a triangular lattice inside a large PWR-type reactor pressure vessel (RPV). A 6-meter in diameter moderator tank is located inside the $\mathrm{RPV}$, containing the moderator at the full operating pressure (11.5 MPa). Power control is achieved by changing the moderator temperature by an external cooling circuit, and by the use of 12 of the 18 oblique control rods. Reactor shutdown is obtained by all the 18 oblique CRs and by an ad hoc system (the KBC system) that allows to dose a uniform Boron concentration into the moderator and coolant. Instead, during some accidental conditions, a fully independent shutdown system (the JDJ) allows the fast injection of a highly concentrated Boron solution in the moderator tank [1].

After the definition of a relevant core status with fuel at the burnup equilibrium, a set of neutron cross section libraries were calculated by the lattice physics code HELIOS. These data were used for the setting up of an RELAP53D neutron kinetic (NK) model of the core that was then coupled with an RELAP5-3D thermal-hydraulic (TH) model of the whole plant. The TH model is based on 280 Fuel Channels (FCs) and a 3D moderator tank nodalization. The 3D NK model is representing all the FCs, the reflectors, and the oblique Control Rods (CRs). The boundary conditions for the reconstruction of the Boron clouds, injected in the moderator tank by the shut-down emergency system, were derived by previously executed Computational Fluiddynamics (CFD) analyses by the CFX code [2].

The evolution of the Boron concentration of the clouds was then reconstructed in the 3D TH moderator tank, using an automatic routine and several time-dependent junctions. 


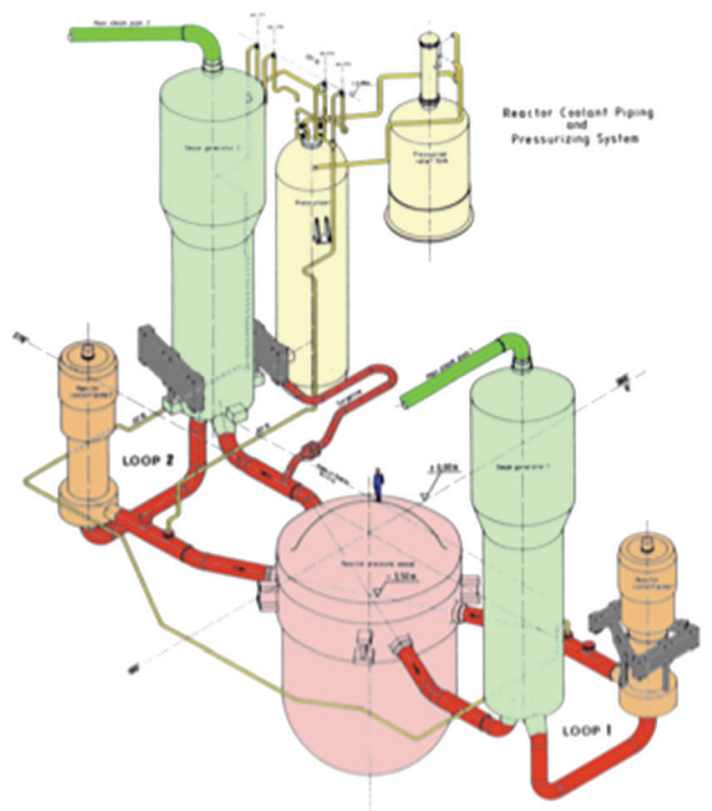

FIgUre 1: Atucha-2 NPP layout.

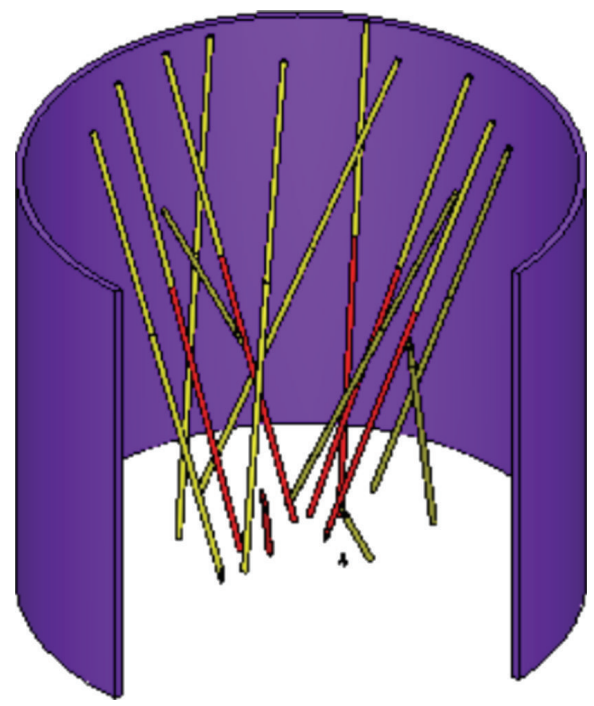

FIgURe 2: Atucha-2 KENO-VI CR model.

All these data were used as a boundary and initial conditions (BICs) for the steady state and transients calculations.

\section{Monte Carlo Models Development}

The geometrical complexity of this design (e.g., oblique CR, each one divided in to an upper and lower sections, 451 independent FCs, etc.) required the adoption of 3D Monte Carlo transport models (see Figure 2).

Two independent, full-core, pin-by-pin models were developed for the MCNP5 [3] and KENO-VI [4] codes, taking into account all the main characteristics, for example, the different insertion angles of the CRs and their different upper and lower structure, FC Zircaloy insulation sheets, and the core barrel (see Figures 3 and 4).

These model were successfully used for CZP criticality calculation. Further development of these models consider 10 levels of axial discretization to take into account the axial differences in temperature and density.

\section{Sensitivities and Criticality Calculations}

Preliminary criticality calculations were run at cold zero power (CZP), and sensitivities analyses were performed assessing the effects of several geometrical details on the results. The effects of initial source distribution and of different continuous energy (e.g., ENDF/B-VIv8, ENDF/BVII) and multigroup cross sections libraries were also investigated. Results with low variance were obtained running about 100 million of active neutron histories. Finally, reference criticality calculations were produced simulating CZP conditions for the core at the beginning of life (BOL).

Several cases were simulated to investigate the effects of control rod insertion, different Boron concentration, flux distribution, and beta delayed factors. In Table 1 is reported the results of sensitivity of Boron concentration in the case of all rod inserted (ARI), then in Figures 5 and 6 the flux distribution is given.

Differences of the order of hundreds pcm were found from comparison between MCNP and KENO-VI codes. Such differences are due to the different Xsec library used, or the ENDF/B-VI.6 continuous energy (CE) Xsec by MCNP5 and the 289 energy groups Xsec libraries derived from ENDF/B-VI.8 by KENO-VI.

The MCNP5 CZP results were used in the validation process of the Atucha-2 RELAP5-3D [5] 3D neutron kinetics(NKs-) thermal-hydraulic model and also developed by the GRNSPG. Thus, a comparison between the CZP, all rods out solutions obtained by MCNP5, and the 3D NK NESTLE routine [6] of RELAP5-3D was performed, allowing to validate both the applied coupling methodology as the system code model developed.

\section{CR Stochastic Volume Calculations by MCNP5 Model}

A further application of the developed Atucha-2 MCNP5 model was the stochastic volume calculations of the CRs [7].

As it can be easily understood from Figure 7, each CR is intersecting in several different ways the various 4510 hexagonal prisms composing the 3D NK mesh structure of the NESTLE code. Therefore, in order to calculate appropriate CR weighting factors, several cases of intersection had to be identified and the relative cell CR volumes calculated.

The developed procedure was the following. The CR volume to be measured was enclosed in a sphere, and an inward spherical distribution of neutron particles was employed for flooding the objects, that is, the CR and the intersected hexagonal prisms. A flux tally got the resulting volume calculation (see Figure 8).

In order to get a low variance on each flux (i.e., volume) tally, an automatic $\mathrm{C}$ routine was developed for calculating 


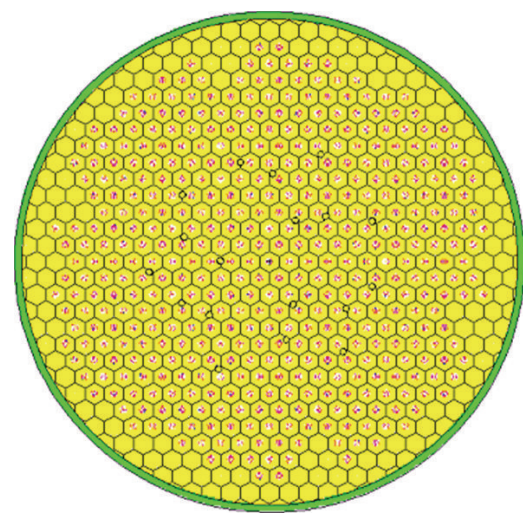

(a)

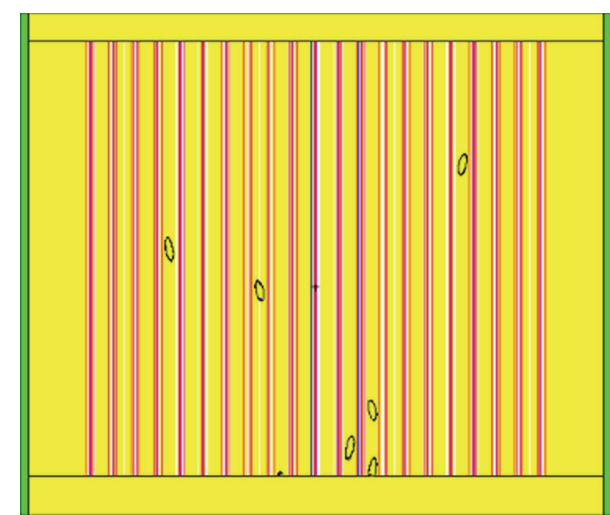

(b)

FIgURE 3: Atucha-2 MCNP5 3D model, planar and axial view.

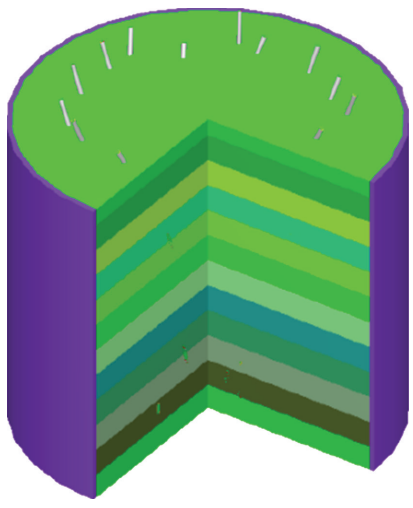

(a)

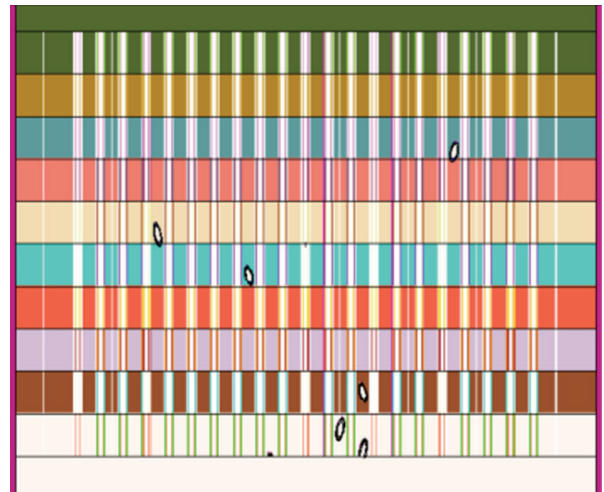

(b)

Figure 4: Atucha-2 KENO-VI and MCNP5 models, ten levels of axial detail.

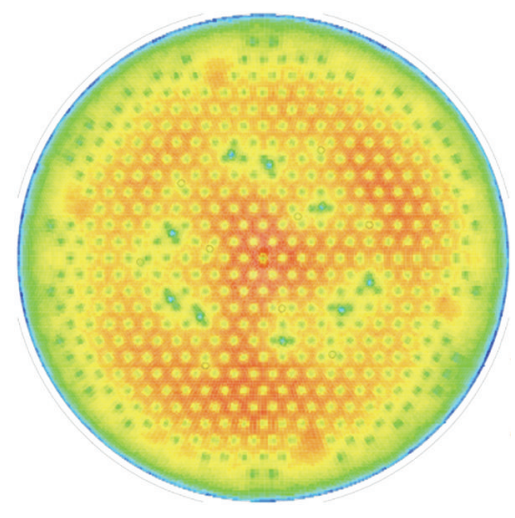

(a)

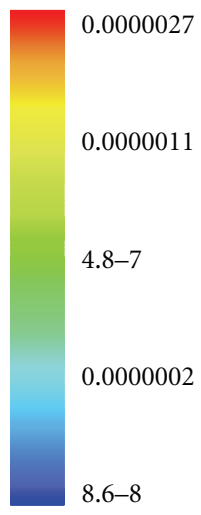

$8.6-8$

FIGURE 5: Results from the Atucha-2 MCNP5 3D model-thermal Flux distribution, planar and axial view.

TABLE 1: Criticality results, CZP in ARI case from KENO-VI and MCNP5 core.

\begin{tabular}{lccccc}
\hline Boron concentration $[\mathrm{ppm}]$ & MCNP $k_{\text {eff }}$ & $\sigma[\mathrm{pcm}]$ & KENO-VI $k_{\text {eff }}$ & $\sigma[\mathrm{pcm}]$ & Differences $($ KENOVI - MCNP5) $[\mathrm{pcm}]$ \\
\hline 0 & 1.08294 & 5 & 1.08753 & 6 & 459 \\
16 & 0.96727 & 6 & 0.97153 & 6 & 426 \\
\hline
\end{tabular}




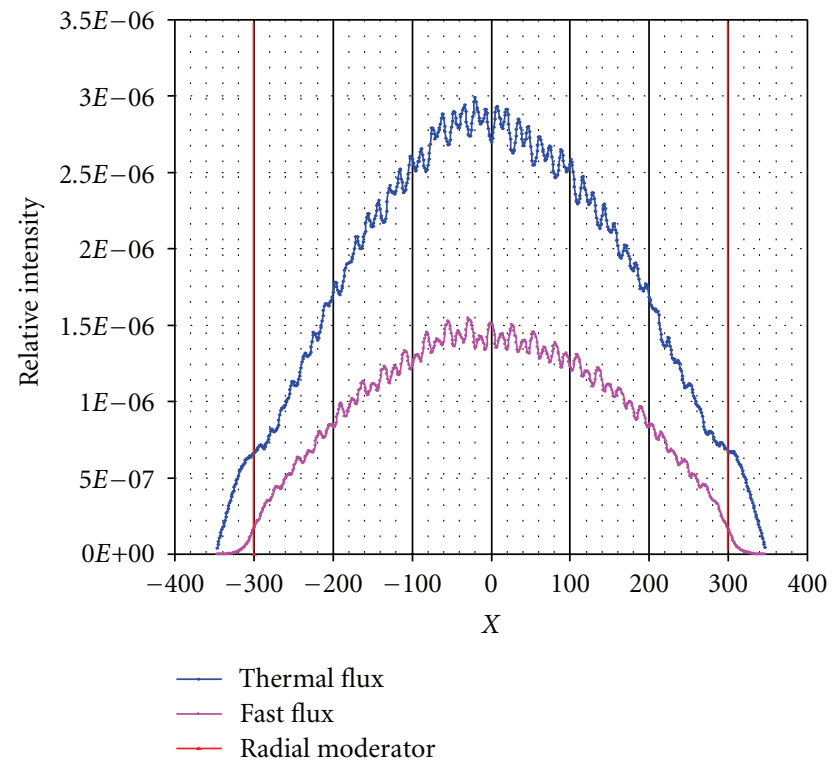

FIgURE 6: Results from the Atucha-2 MCNP5 3D model-thermal and fast Flux distribution.

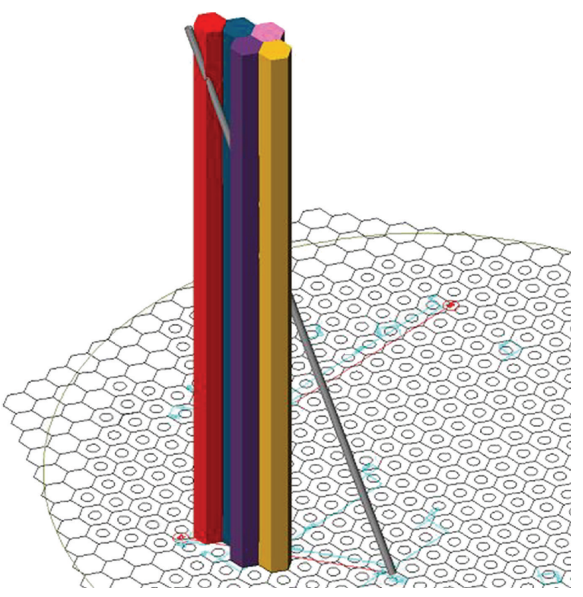

(a)

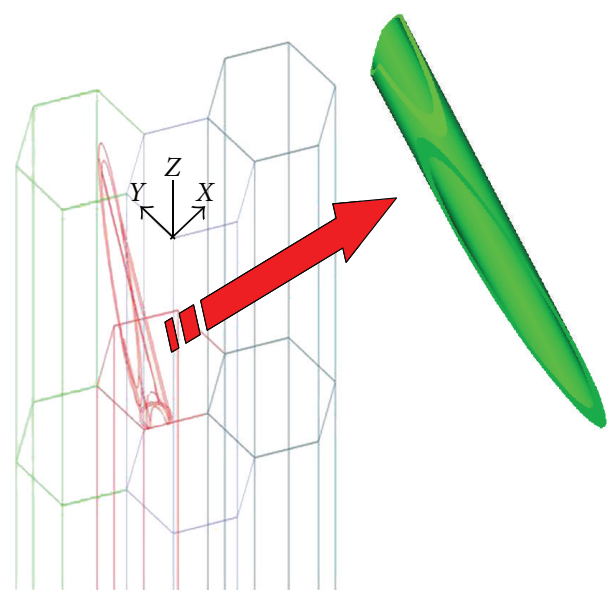

(b)

FIGURE 7: Sketch of a CR and its crossing with 3D NK hexagonal cells.
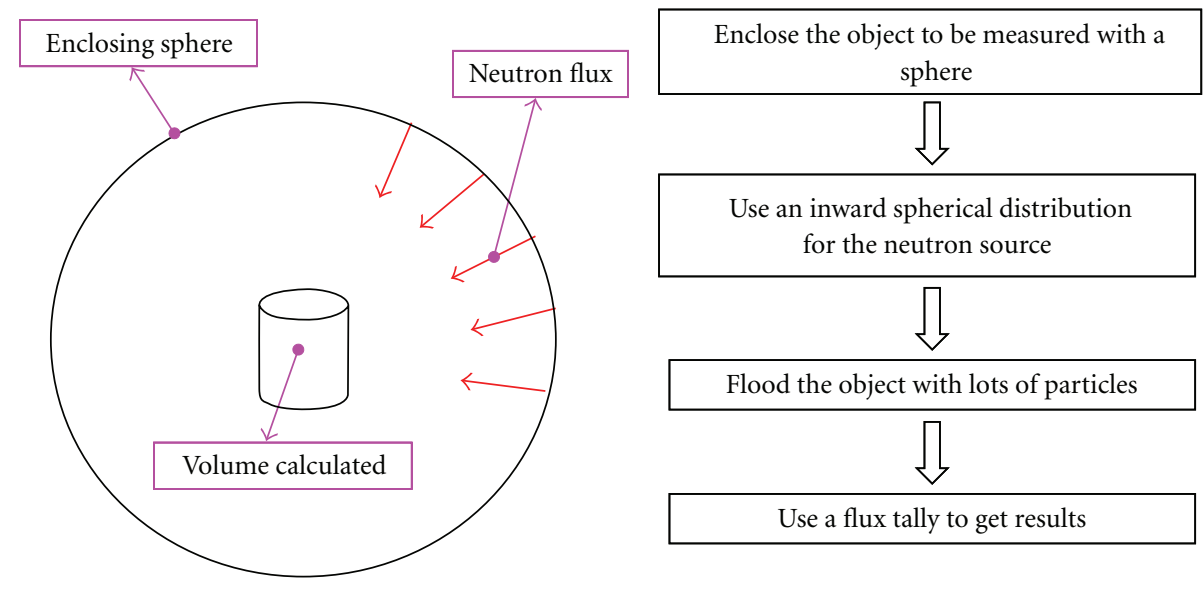

Figure 8: Stochastic cell volume procedure by MCNP5 tally. 


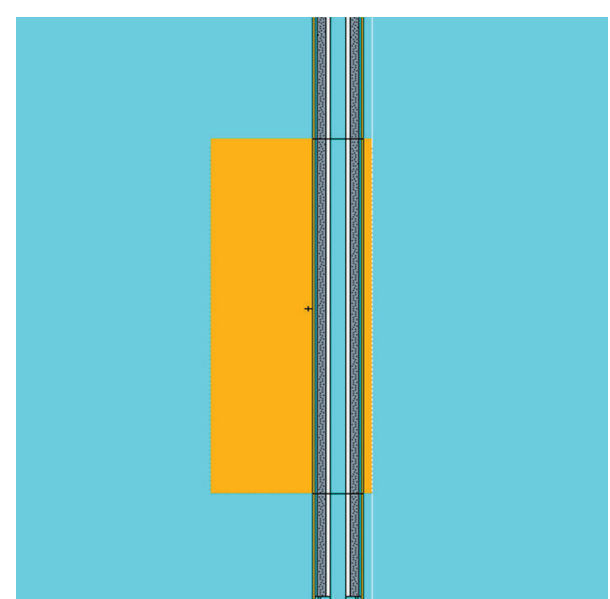

(a)

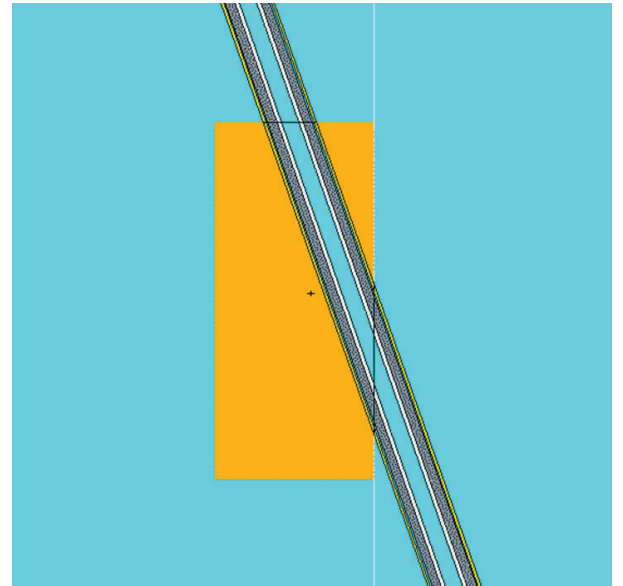

(b)

Figure 9: 2D HELIOS and 3D MCNP5 models.

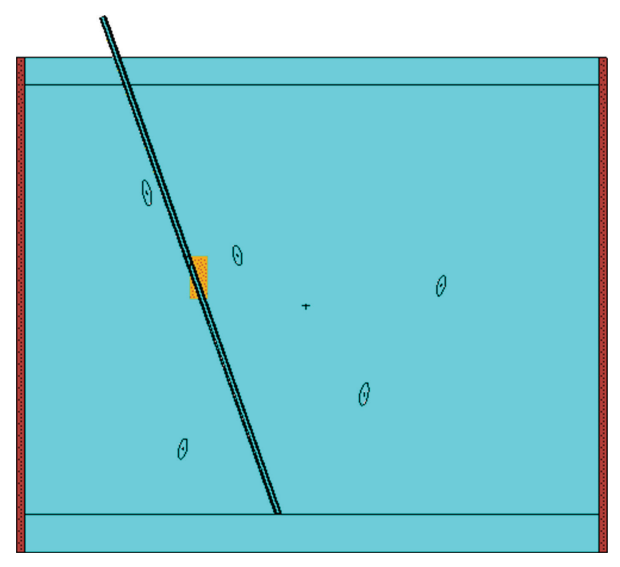

(a)

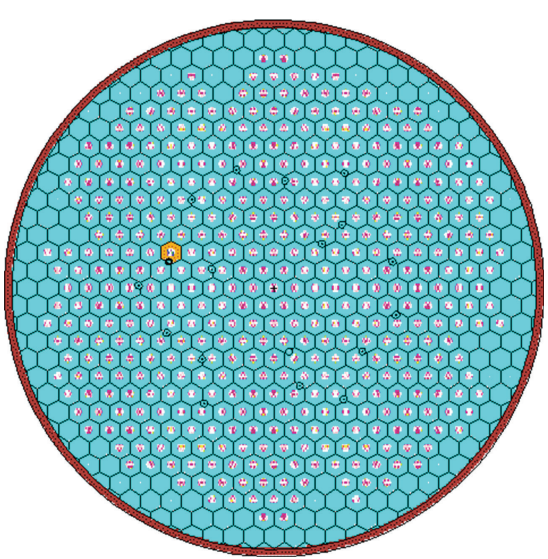

(b)

FIGURE 10: Equivalent NESTLE composition in MCNP5 core model, axial view.

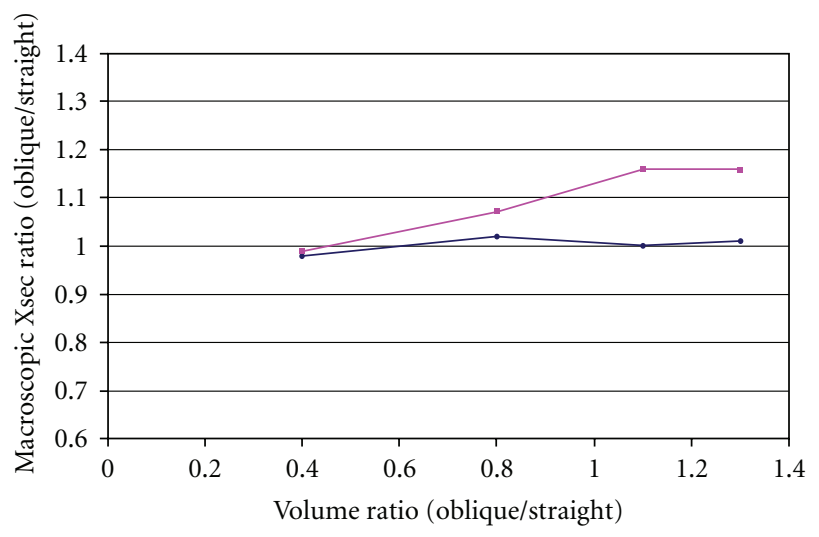

$\rightarrow$ Macroabsorption Xsec (fast group)

$\rightarrow$ Macroabsorption Xsec (thermal group)

(a)

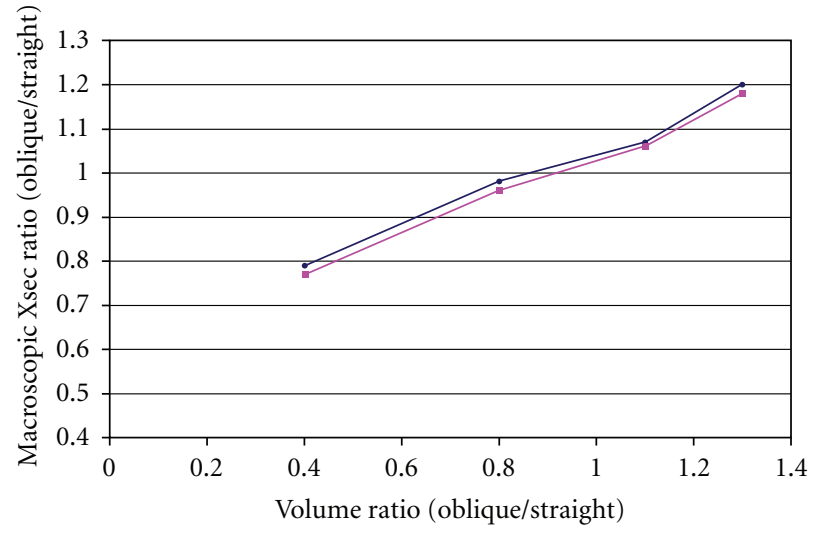

$\rightarrow$ Macroabsorption Xsec (fast group)

$\rightarrow$ Macroabsorption Xsec (thermal group)

(b)

Figure 11: 3D effects on absorption macroscopic cross sections (gray CR and black CR). 


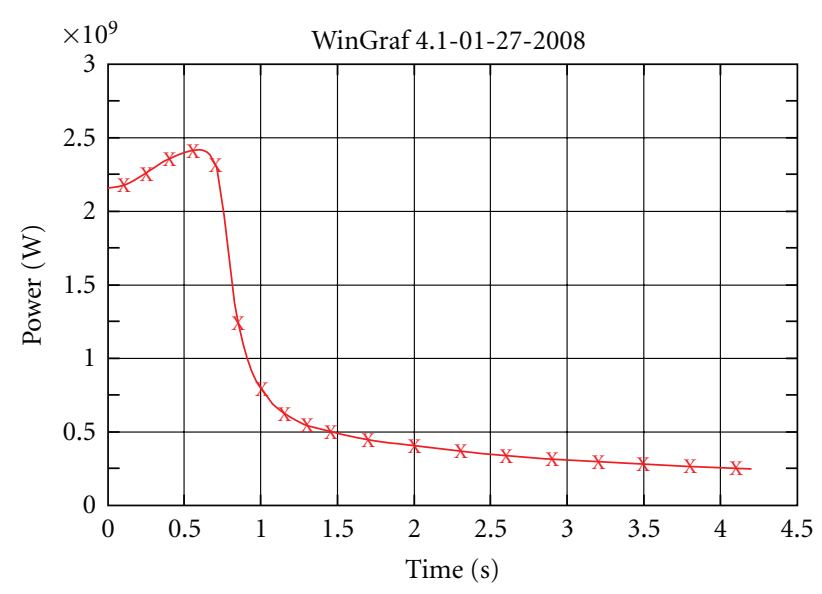

XXX CNA2_01A_LOCA rkotpow0

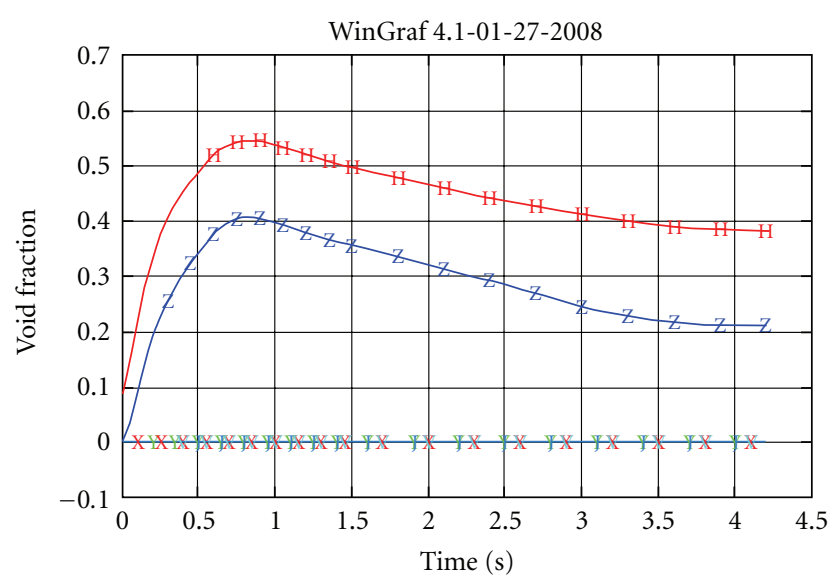

$\begin{array}{ll}\text { XXX } & \text { CNA2_01A_LOCA voidg250040000 } \\ \text { YYY } & \text { CNA2_01A_LOCA voidg250080000 } \\ \text { ZZZ } & \text { CNA2_01A_LOCA voidg250120000 } \\ \text { VVV } & \text { CNA2_01A_LOCA voidg272040000 } \\ \text { JJJ } & \text { CNA2_01A_LOCA voidg272080000 } \\ \text { HHH } & \text { CNA2_01A_LOCA voidg272120000 }\end{array}$

(b)

(a)

FIgURE 12: Reactor power (W) and void fraction in central and hot channel.

the optimal dimension of the enclosing sphere. Moreover, 100 million of neutron histories were employed to minimize statistical fluctuations.

This volume calculation procedure underwent a validation process comparing volumes calculated by MCNP5 with volumes calculated by the Autodesk AUTOCAD model, developed for a single CR (see Figure 7). The error on the MCNP5 volumes calculations is about few percent, ranging from a maximum of $+9.7 \%$ to a minimum of $+0.34 \%$. The average error on the whole calculations was resulted to be about $+2 \%$.

A C/PERL routine allowed to automatically create the several MCNP5 input files for the calculations of all the possible CR volumes resulting from the intersection of the 18 CRs with 3D NK hexagonal meshes. Actually, symmetry considerations allowed to reduce the number of CRs intersections to be investigated to $10 \mathrm{CRs}$, thus resulting in $10 * 40$ $=400$ volumes calculations. In a successive step, the obtained values were integrated in another procedure for the NESTLE CR cross section weighting.

\section{Cross Section Evaluation}

The MCNP5 core model was also applied for the calculations of corrective factors for the CR cross sections libraries. These libraries were developed using the two-dimensional lattice physics code HELIOS, that can not take into account the three-dimensional geometrical effects (i.e., the oblique CR) $[2,8]$. Therefore, MCNP5 calculations were run comparing results for the realistic model (Figure 9(b)) with an HELIOS equivalent MCNP5 model (Figure 9(a)).

The developed procedure allowed us to evaluate the effects on a cell macroscopic cross sections (namely, the absorption and the fission cross sections) by the threedimensional geometry (see Figure 10). For performing this estimation, the use of the MCNP5 tallies was exploited.

These averaged rates were obtained calculating with MCNP5 the reaction rate $R_{\text {fiss,abs }}$ in the selected "composition" (NESTLE equivalent 3D cell)

$$
R_{\mathrm{fiss}, \mathrm{abs}}=\left(\frac{1}{V}\right) \int d E d V \sum_{\text {fiss,abs }}(E) \Phi(E),
$$

where $\Phi(E)$ is the flux, $\sum_{\text {fiss,abs }}(r, E)$ is the macroscopic (fission or absorption) cross section, and $V$ is the volume used to normalize the tally and calculated by MCNP5 with the stochastically method.

Thus, the averaged macroscopic cross section $\overline{\sum_{a, f}}$ was easily obtained by the following formula:

$$
\overline{\sum_{\text {fiss,abs }}}=\frac{R_{\text {fiss,abs }}}{\iint d E d V \Phi(r, E)} .
$$

Atucha-2 has two types of CR, differing by the absorber material (hafnium and stainless steel). For each type of CR, 5 cases were simulated, one considering an MCN5 model equivalent to the HELIOS model (straight CR) and 4 cases using a realistic MCNP5 model (oblique CR). Thus, the effects of possible insertion modes of the CR on the macroscopic cross sections were evaluated.

An example of results can be seen in Figure 11, for example, for gray (stainless steel) and black (hafnium) CRs. It is shown that, generally, a kind of linear law exists for the absorption cross section, with the increase of the ratio oblique volume/straight volume of a CR in the cell. The 3D effects seem negligible when considering the fast absorption cross section for the gray CRs. 


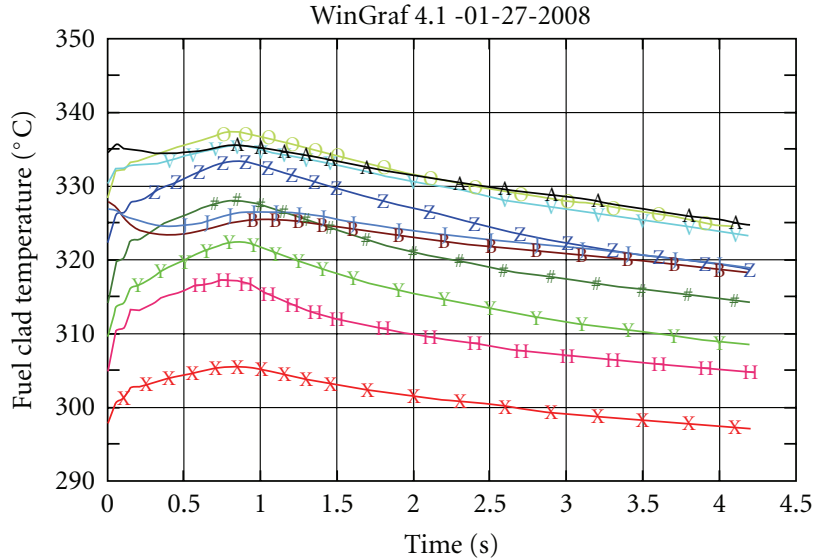

$\begin{array}{cl}\text { XXX } & \text { CNA2_01A_LOCA httemp250100209 } \\ \text { YYY } & \text { CNA2_01A_LOCA httemp250100409 } \\ \text { ZZZ } & \text { CNA2_01A_LOCA httemp250100609 } \\ \text { VVV } & \text { CNA2_01A_LOCA httemp250100809 } \\ \text { JJJ } & \text { CNA2_01A_LOCA httemp250101009 } \\ \text { HHH } & \text { CNA2_01A_LOCA httemp272100209 } \\ \text { \#\#\# } & \text { CNA2_01A_LOCA httemp272100409 } \\ \text { OOO } & \text { CNA2_01A_LOCA httemp272100609 } \\ \text { AAA } & \text { CNA2_01A_LOCA httemp272100809 } \\ \text { BBB } & \text { CNA2_01A_LOCA httemp272101009 }\end{array}$

FIgURE 13: Fuel clad temperatures for central and hot channel.

\section{The 0.1 Large Break LOCA}

The results obtained by the Monte Carlo codes (i.e., the stochastic volume calculation and the corrective factor for the cross section) were implemented in the RELAP5-3D neutron kinetic model. An application of this validated model is the 0.1 a Large Break LOCA in Cold Leg 2 (CL2), one of the design basis accidents (DBAs) that has to be considered for the Atucha-2 licensing. The transient is initiated by the instantaneous opening (i.e., 3-10 seconds) of the break located between the RPV nozzle and the CL2. Boron injection by the shut-down emergency system starts at +0.63 seconds from the beginning of the transient and terminates at +3.91 seconds. Scram signal is actuated after +0.07 seconds, and the CR are completely inserted after +3.57 seconds. The transient analysis was performed for the first ten seconds. The results are presented in Figures 12 and 13.

As it is shown in Figure 12(a), the power increases during the first half second of the transient because of the positive void coefficient. Figure 12(b) represents also the void fraction trend for the central and hot channel. The actuation of the emergency Boron injection system and CRs insert enough negative reactivity (see Figure 12) to quench the power excursion. Figure 13 demonstrates that fuel clad temperatures are not of safety concern, and also for the hot channel.

\section{Conclusion}

The complex Atucha-2 geometrical design required the adoption of advanced 3D Monte Carlo calculations. The capabilities of two of the most advanced codes (MCNP5 and KENO-VI) allowed us to perform reference calculations with an unprecedented level of details. Moreover, MCNP5 flexibility was exploited for an automatic calculation of CR weighting factors, allowing for a great simplification of the necessary job for the 3D NK model development. Finally, further applications of these models are envisaged in the near future (e.g., criticality calculations with core at equilibrium burnup).

\section{References}

[1] C. Parisi, "Definition of a relevant core status," GRNSPG Report SIR-2.1, rev. 1, 2007.

[2] F. Moretti, F. Terzuoli, and D. Melideo, "CFD Transient Analyses for CNA-2," GRNSPG Report TFR-6, Rev. 0, 2007.

[3] X-5 Monte Carlo Team, MCNP-A general Monte Carlo NParticle Transport Code, Version 5, vol. 1, LA-UR-03-1987, 2003.

[4] D. F. Hollenbach, L. M. Petrie, and N. F. Landers, "KENO-VI: a General Quadratic Version of the KENO Program," ORNL/TM2005/39 Version 5.1 Vol. II, Book 3, Sect. F17, 2005.

[5] RELAP5-3D Code Manual, "Volume I: Code Structure, System Models, And Solution Methods," INEEL-EXT-98-00834, ver. $2.4,2005$.

[6] P. Turinsky et al., Few-Group Neutron Diffusion Equation Solver Utilizing the Nodal Expansion Method for Eigenvalue, Adjoint, Fixed-Source Steady-State and Transient Problems, Electric Power Research Center, North Carolina State University, Raleigh, NC, USA, 1994.

[7] K. M. Case, F. de Hoffmann, and G. Placzek, Introduction to the Theory of Neutron Diffusion, vol. 1, Los Alamos Scientific Laboratory, 1953.

[8] C. Parisi and M. Pecchia, "Calculation of Cross Section weighting coefficients for the Atucha2 CR model," GRNSPG Report NEU-3.6.1, rev. 0, 2008. 

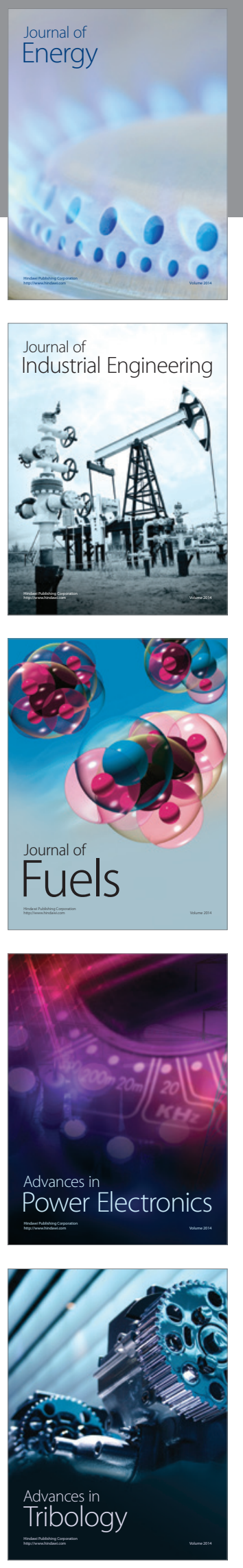
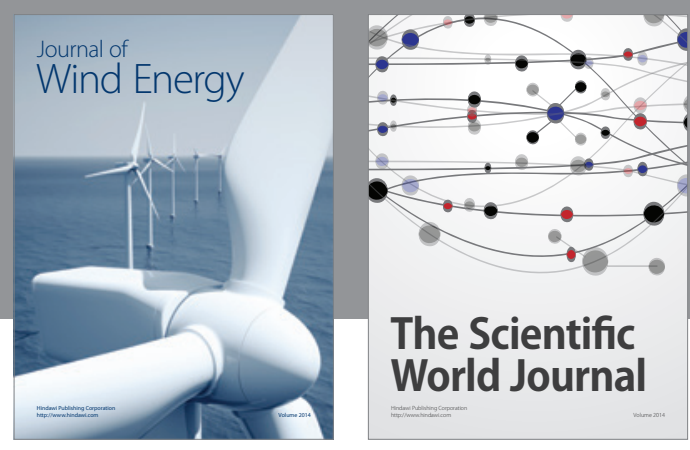

The Scientific World Journal

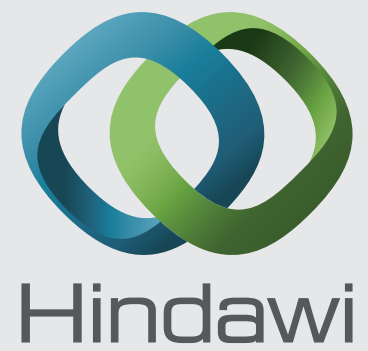

Submit your manuscripts at http://www.hindawi.com
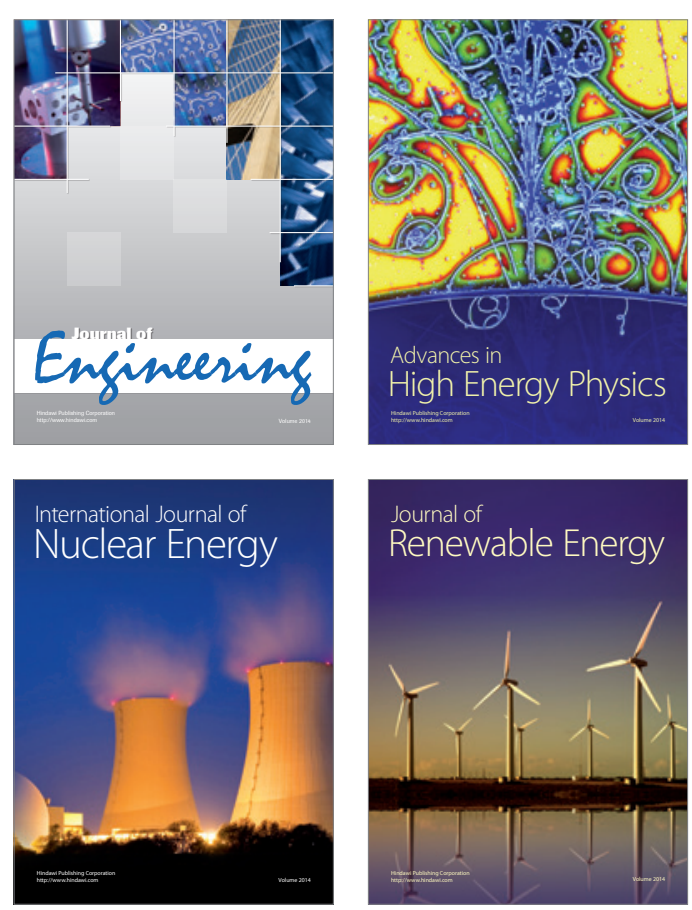

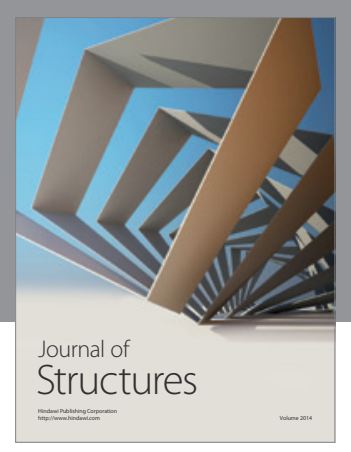

Rotating
Mechinery
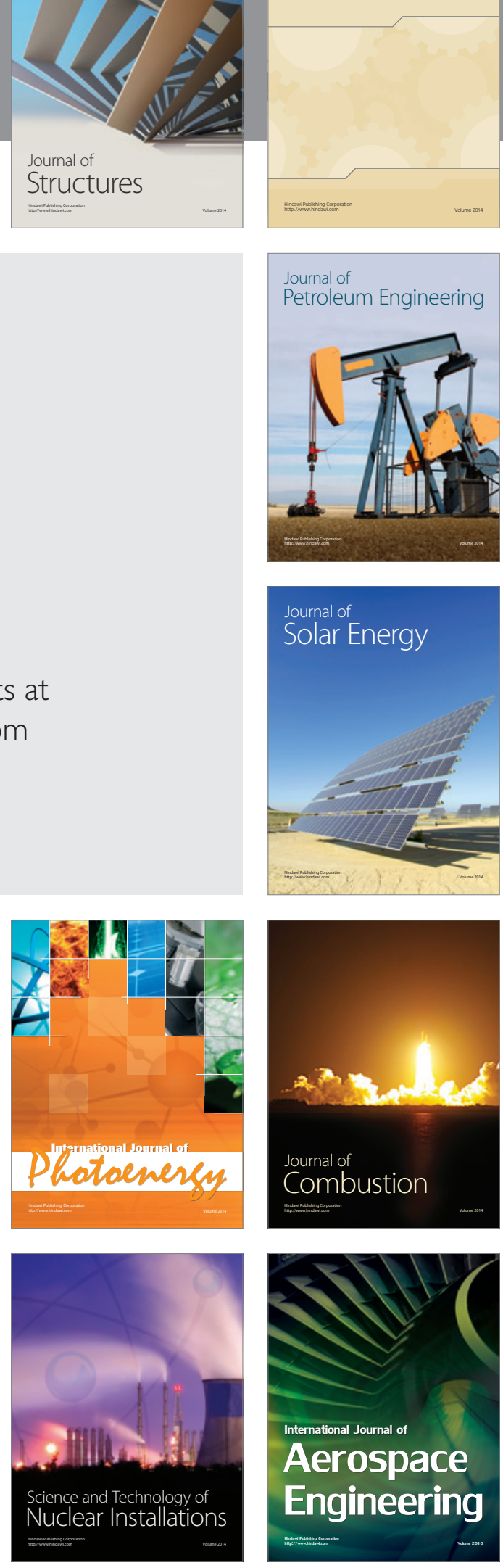